affected, the risks to siblings are 30-40\% (50\% if both parents are affected). A high proportion of probands and their siblings develop EEG abnormalities $3-5$ years after the febrile seizure, including generalized spike-and-wave and a photoconvulsive response (Hauser et al 1985; Millichap, 1968).

\title{
SURGICAL TREATMENT OF INIRACTABLE EPILEPSY
}

Seventy-five children, ages 5 months to 15 years, were treated for intractable seizures in the Neurosurgical Dept. of Washington University School of Medicine, St. Louis, MO, USA. The use of implantable arrays of epidural electrodes facilitated extraoperative electrocorticography (ECOG) and simultaneous video monitoring that provided localizing information prior to cortical excision in 53 patients. The pathological lesions were chronic encephalitis of Rasmussen (9), cortical sclerosis with infantile hemiplegia (7), mesial temporal sclerosis (6), extratemporal sclerosis (6), cortical dysplasia (4), tuberous sclerosis (3), porencephalic cyst (3), Sturge-Weber (3), polymicrogyria (2), heterotopia (2), occult vascular malformation (1), misc (7). Results were good in 32 (65\%): 16 seizure free and 16 improved control after follow-up of 1-14 years. Gliomas were found in an additional 17 cases and were the most common single cause of intractable seizures; $82 \%$ were seizure free for more than 1 year (mean follow-up of 4.5 years) since surgery. (Goldring $S$. Pediatric epilepsy surgery. Epilepsia 1987; 28 (Suppl 1:S82-102).

COAENT: With an increasing awareness of the adverse effects of antiepileptic drugs on learning and behavior in children (see ped. Neur. Briefs 1987; $1: 20$; Vining EPG et al. Pediatrics 1987; 80: $\overline{165 ;}$ Freeman JM. Epilepsia 1987; 28S:103) the need for alternative therapies becomes more apparent. The ketogenic and MCT diets could be used more frequently, metabolic causes requiring specific therapy (e.g.' biotin, pyridoxine), though rare, should not be overlooked; and psychological factors especially important in the adolescent and young adult should be investigated and remedied. Dr. Goldring offers another alternative in surgical intervention which he believes to be a much under utilized therapeutic approach to intractable epilepsy in children. Although the emphasis and reliance on drugs in the management of seizures cannot be discounted, their promotion must not permit the neglect of preventive and alternative approaches to the child with seizures.

\section{HEAD AND NECK TRAUMA}

\section{ICE BOCKEY INUURIES}

The School of Public Health Institute for Athletic Medicine, and Departments of Orthopedic Surgery and Biomechanical Engineering, University of Minnesota, Minneapolis, MN, conducted an epidemiological study of ice hockey injuries among 12 high school varsity teams in the 1982-83 season. A major finding was a high incidence of concussion (98), accounting for $12 \%$ of the total injuries. In addition, dizziness in $34 \%$, headaches in 30\%, blurred vision in 12\%, and tinnitus in 11\%, followed a blow to head or neck. Residual symptoms, including neck pain, back pain, reduced strength in upper extremities, were reported in $28 \%$ of players with a blow to head, neck or back. The older, taller, heavier player was injured most frequently, except that the risk to the 14-year old player 
was equal to that for 18-year olds. Injured players had greater playing experience, and defense and wings accounted for the highest percentage of injuries.

Injuries occurred primarily during competition (82\%) and breakout plays accounted for $23 \%$ of head injuries. Colliding with another player (35\%) and hitting the boards $(20 \%)$ were the major mechanisms of injury. Playing hockey to allay tension and aggressions resulted in a risk of concussion four times that of alternative motivations such as enjoyment of the game, a scholarship for college, or peer relations. The use of the face mask may have promoted a more aggressive style of play and also increased risk of concussions and other injuries. The authors advocate elimination of body checking, the cushioning of boards, and the use of breakaway goal posts. (Gerberich SG, Finke R et al. Child's Nerv Syst 1987; $3: 59-64$ ).

COMMENT: These statistics are alarming. Other studies have shown that one-third of all hockey related injuries have occurred in children aged 5 to 14 years. Epidemiological studies are needed in the younger age groups and Little Leagues. Coaches should be aware that the developsent of vertebrae and adjoining cartilage is incomplete in children and susceptibility to neck injury is greater than in adults. Coaches, players and parents should be better educated regarding potential risks of serious injuries associated with collision forces to the head and neck in young hockey enthusiasts and aggressive behavior should not be condoned.

Other sports-related CNS injuries in children and adolescents reviewed by Lehman LB (Postgrad Med Sept 15 1987; 82:141) include closed head and cervical spine injuries associated with boxing, wrestling, judo, karate, gymnastics, football, soccer, and rugby. The most important step in reducing cervical spine injury has been the elimination of "spearing", which involves the use of the helmeted skull as a battering ram. Episodes of mild cerebral concussion, a frequent occurrence in competitive sports, are deleterious. Recently, the cheerleaders "pyramid" formation has been implicated in a number of neurological injuries and even deaths.

\section{DEMYELINATING DISEASES}

\section{MULTIPLE SCLERDSIS}

Nine MS clinics from the Canadian MS study group collaborated in a retrospective study employing questionnaires about the MS populations and with particular reference to cases with onset before age 16 years. Childhood MS was more frequent in girls and their overrepresentation was even greater in the following subgroups: those with sensory initial symptoms, complete recovery from initial episode, a nonprogressive clinical course, and lower disability scores. Conversely, boys were overrepresented in subgroups of patients with no recovery from the initial episode and progressive course.

MS in girls has an early onset, is usually heralded by sensory symptoms that frequently remit completely, has a relapsing-remitting course and a slow progression. Boys with MS have a poorer prognosis and progressive course, usually related to late onset of the disease. The familial incidence was 28\%. CSF showed normal IgG levels in 59\% and 